\title{
Stretching the performance of wearable Li-ion batteries
}

\author{
Colm O’Dwyer \\ NPG Asia Materials (2014) 6, e139; doi:10.1038/am.2014.97; published online 31 October 2014
}

As advancements are made in wearable technology, including the development of portable devices that can function when stretched or bent, so too must the ways by which these devices generate and store power. ${ }^{1}$ For true portability of flexible smartphones, interactive bracelets and smart textiles for example, higher energy-density batteries need to be part of the 'fabric' of the device. Researchers from Fudan University in Shanghai demonstrated that a wire-shaped lithium-ion battery can be fabricated from a composite pairing of aligned yarns of active materials, sheathed in a heatshrinkable tube. ${ }^{2}$

These stretchable wire-shaped batteries, depicted in Figure 1, deliver an energy density of $27 \mathrm{Wh}-$ $\mathrm{kg}^{-1}$, surpassing wire-shaped supercapacitors. ${ }^{3}$ They are flexible and light, and retain 97\% capacity after 1000 bending cycles. On using a modified spring-like structure to accommodate elastic stretching up to $100 \%$, they maintain $84 \%$ capacity after 200 cycles. These stretchable batteries are safe and prevent dendrite formation in a close-packed woven pairing of intercalation-mode electrodes, since they are free of metallic lithium.

These batteries can also be woven into lightweight, flexible and stretchable textiles, and operate without damage. As a demonstration, the team showed that a fully charged $10-\mathrm{cm}$-long wireshaped battery powered nine light-emitting diodes for $\sim 60 \mathrm{~s}$, and operated even when bent into different shapes.

The findings should motivate further research into the energy storage options for reliable, safe and high-performance wearable technology, and provide a basis for device-compatible Li-ion battery architectures $^{4}$ for powering flexible portable electronics. Seamless integration with the device shape and structure and improvement in energy density remain a challenge. In the future, shape-adaptable batteries could be integrated with power from piezoelectric, thermoelectric, photovoltaic and other power sources.

Department of Chemistry and Tyndall National Institute, University College Cork, Cork, Ireland

E-mail: c.odwyer@ucc.ie

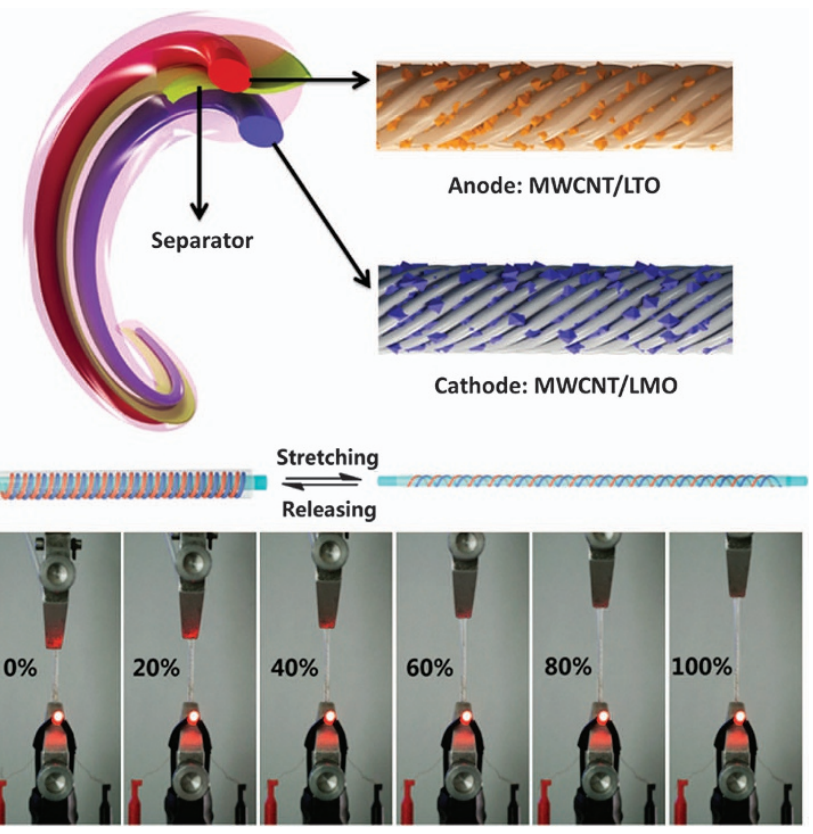

Figure 1 (Top) Structure of the flexible wire-shaped lithium-ion battery composed of aligned woven yarns of active materials. (Bottom) The wire-shaped battery can power a LED when stretched to double its length.

1 Jeong, G. S., Baek, D.-H., Jung, H. C., Song, J. H., Moon, J. H., Hong, S. W., Kim, I. Y. \& Lee, S.-H. Solderable and electroplatable flexible electronic circuit on a porous stretchable elastomer. Nat. Commun. 3, 977 (2012).

2 Ren, J., Zhang, Y., Bai, W., Chen, X., Zhang, Z., Fang, X., Weng, W., Wang, Y. \& Peng, H. Elastic and wearable wire-shaped lithium-ion battery with high electrochemical performance. Angew. Chem. Int. Ed. 53, 7864 (2014).

3 Lee, J. A., Shin, M. K., Kim, S. H., Cho, H. U., Spinks, G. M., Wallace, G. G., Lima, M. D., Lepró, X., Kozlov, M. E., Baughman, R. H. \& Kim, S. J. Ultrafast charge and discharge biscrolled yarn supercapacitors for textiles and microdevices. Nat. Commun. 4 1970 (2013).

4 Osiak, M., Geaney, H., Armstrong, E. \& O'Dwyer, C. Structuring materials for lithium-ion batteries: advancements in nanomaterial structure, composition, and defined assembly on cell performance. J. Mater. Chem. A 2, 9433 (2014).

cc)(하 This work is licensed under a Creative Commons AttributionNonCommercial-NoDerivatives 4.0 International License. The images or other third party material in this article are included in the article's Creative Commons license, unless indicated otherwise in the credit line; if the material is not included under the Creative Commons license, users will need to obtain permission from the license holder to reproduce the material. To view a copy of this license, visit http://creativecommons.org/ licenses/by-nc-nd/4.0/ 